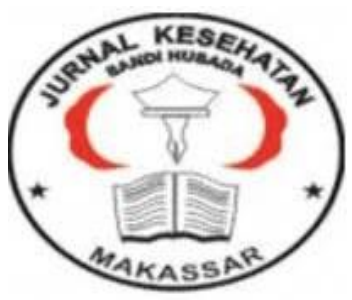

\author{
Jurnal Ilmiah Kesehatan Sandi Husada \\ hhttps://akper-sandikarsa.e-journal.id/JIKSH \\ Vol 10, No, 2, Desember 2019, pp;161-168 \\ p-ISSN: 2354-6093 dan e-ISSN: 2654-4563 \\ DOI: $10.35816 /$ jiskh.v10i2.139
}

\title{
Perbandingan Efek Antara Mobilization of the Nervous as System Active Exercise Terhadap Perubahan Nyeri dan Fleksibilitas Penderita Low Back Pain
}

Comparison of Effects between Mobilization of the Nervous as System Active Exercise on Pain Change and Flexibility of Patients with Low Back Pain

\section{Djohan Aras}

Program Studi Fisioterapi, Fakultas Keperawatan, Universitas Hasanuddin, Makassar

\section{Artikel info}

Artikel history:

Received; 30 November 2019

Revised; 05 Desember 2019

Accepted; 13 Desember 2019
Abstract. Low Back Pain (LBP) is a disturbance attacked the lower area of the back due to various either musculoskeletal problems or incorrect mobilization. LBP can produce pain sensation and diminishing lumbal flexibility so that it disturbs patient's activity. Mobilization of the Nervous as System (MONAS) and Active Exercise are training methods used to decrease pain and increase flexibility in LPB patients. This research aimed to identify The Comparison between MONAS and Active Exercise on Changes of Pain and Flexibility in Patients Suffering from Low Back Pain (LBP). The recent study was an experimental study with pre test- post test two group design. The sampling was conducted by using purposive sampling method. The number of samples was 22 samples divided into 2 groups namely groups of MONAS and Active Exercise. Each group consisted of 11 respondents. The measurement tools used were Visual Analogue Scale (VAS) to measure the pain level and Modified Schober Test (MST) to assess the flexibility. This research used paired $t$-test as test of effect while independent sample t-test was used as comparative test. Analysis of paired sample t-test showed that there was changes in pain and flexibility levels in LBP patients after administration of either MONAS ( $p$ value $=0.000$ ) or Active Exercise ( $p$ value $=0.000)$. Independent sample $t$-test gave $p$ value $=0.658$ and 0.729 for pain and flexibility, respectively. As conclusion, there was no significant difference between MONAS and Active Exercise either on pain or flexibility levels

Abstrak. Low Back Pain merupakan gangguan yang dirasakan di punggung bagian bawah yang disebabkan oleh berbagai gangguan musculoskeletal maupun mobilisasi yang salah. LBP dapat menyebabkan timbulnya nyeri dan penurunan fleksibilitas lumbal sehingga mengganggu aktivitas penderitanya. Mobilization of the Nervous as System (MONAS) dan Active Exercise merupakan latihan yang dapat digunakan untuk menurunkan nyeri dan meningkatkan fleksibilitas pada penderita LBP. Penelitian ini bertujuan untuk mengetahui perbandingan 
antara mobilization of the nervous as system dan active exercise terhadap perubahan nyeri dan fleksibilitas pada penderita low back pain (LBP). Penelitianini merupakan penelitian eksperimental dengan desainpenelitian prebtest-post test two group design. Teknik pengambilan sampel yaitu purposive sampling dengan jumlah sampel sebanyak 22 orang dibagi dalam 2 kelompok, yaitu kelompok MONAS dan Active Exercise. Masing-masing kelompok beranggotakan 11 responden. Alat ukur yang digunakan adalah Visual Analogue Scale (VAS) untuk mengukur nyeri dan Modified Schober Test (MST)untuk fleksibilitas. Penelitian ini menggunakan uji paired sampel T test sebagai uji pengaruh dan uji perbandingan menggunakan uji Independent sampel T test. Hasi penelitan dengan uji paired samplet-test menunjukkan terdapat perubahannyeri dan fleksibilitas pada penderita LBP setelah pemberian MONAS dengan nilai $p=0,000$ dan Active Exercise dengan nilai $p=0,000$. Sedangkan hasil uji independent sample t-test pada nyeri diperoleh nilai $p=0,658$ sedangkan fleksibilitas $p=0,729$ yang artinya tidak ada perbedaan yang signifikan antara MONASdan Active Exercise baik terhadap nyeri maupun fleksibilitas.

Keywords:

Nyeri;

Fleksibilitas;

Mobilization of the Nervous

as System (MONAS);

Active exercise;

Low Back Pain;
Coresponden author:

Email: : djohanaras.da@gmail.com

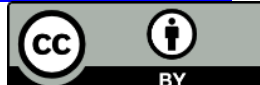

artikel dengan akses terbuka dibawah lisensi CC BY -4.0

\section{PENDAHULUAN}

Low back pain merupakan gangguan musculoskeletal yang dapat disebabkan oleh berbagai penyakit musculoskeletal, gangguan psikologis, dan mobilisasi yang salah. Nyeri yang dirasakan pada punggung bawah berasal dari tulang belakang, otot, saraf atau struktur lain pada daerah tersebut (Kaur, 2016). LBP dapat terjadi karena peregangan otot maupun pergerakan yang kurang pada tulang belakang sehingga menyebabkan otot-otot punggung menjadi lemah atau bahkan mengalami ketegangan. Nyeri yang dirasakan terlokalisasi di bawah sudut iga terakhir dan diatas lipat bokong bawah yang sifatnya lokal maupun menjalar (Tanderi, Kusuma, \& Hendrianingtyas, 2017). Selain itu, terjadinya benturan pada daerah lumbal, adanya kelainan bawaan pada tulang belakang atau terjepitnya saraf spinalis akibat dari pengeroposan tulang maupun penyempitan discus intervebtebralis serta adanya tumor pada lumbal juga dapat mencetuskan terjadinya nyeri pada punggung bawah (Koes, 2017).

Berdasarkan Laporan Hasil Riset Kesehatan Dasar (RISKESDAS) Nasional tahun 2013, prevalensi penyakit musculoskeletal di Indonesia yang pernah didiagnosis oleh tenaga kesehatan yaitu 11,9\% dan berdasarkan diagnosis atau gejala selama survei yaitu 24,7\%. Prevalensi tertinggi berdasarkan diagnosis tenaga kesehatan yaitu di Bali sebesar 19,3\% kemudian Aceh sebanyak 18,3\%, Jawa Barat 17,5\%, dan Papua lebih dari $15,4 \%$. Adapun prevalensi penyakit sendi berdasarkan diagnosis tenaga kesehata atau tertinggi yaitu di Nusa Tenggara Timur sebanyak 33,1\% kemudian Jawa Barat 32,1\% dan diikuti Bali sebesar 30\% (RI,2013).

Beberapa teknik yang digunakan dalam penanganan LBP adalah Mobilization of the Nervous as System (MONAS) atau mobilisasi saraf dan latihan aktif atau active exercise. Mobilisasi saraf dengan metode slump technique bertujuan untuk mengembalikan pergerakan di sekitar 
permukaan saraf (mechanical interface) dan melepaskan perlengketan jaringan saraf dengan jaringan ikat sekitarnya, meningkatkan aliran darah, dan mengurangi nociceptive impulse (Poluan \& Aras, 2018). Selain itu juga melibatkan peregangan pada otot punggung dan hamstring yang menyumbang peningkatan fleksibilitas otot. Hal ini efektif dalam mengurangi rasa sakit pasien (Yuliartha, Silakarma, \& Bagiada, 2017). Active exercise berupa ROM exercise pada lumbal merupakan latihan aktif dengan berbagai gerakan seperti fleksi, ekstensi, lateral fleksi, dan rotasi. Latihan ROM dapat menimbulkan rangsangan sehingga meningkatkan aktivasi dari kimiawi neuromuskuler dan muskuler (Safa'ah \& Srimurayani, 2017). Latihan ini bertujuan untuk memelihara fleksibilitas dan mobilitas sendi8. Berdasarkan uraian tersebut, peneliti tertarik untuk meneliti perbedaan efek antara MONAS dengan Active exercise terhadap perubahan nyeri dan fleksibilitas pada LBP.

\section{Metode}

Penelitian ini dilaksanakan di Klinik Physio Sakti dan RS. Dr. Tadjuddin Chalid. Penelitian ini menggunakan jenis rancangan two group sample dengan menggunakan desain penelitian pre test-post test two group design. Populasi dalam penelitian ini berjumlah 28 orang responden pasien LBP yang berkunjung di Klinik Physio Sakti dan RS. Dr. Tadjuddin Chalid. Sampel penelitian berjumlah 22 orang yang telah memenuhi kriteria inklusi dan eksklusi kemudian dibagi ke dalam 2 kelompok, yaitu kelompok MONAS dan kelompok Active Exercise. Masing- masing kelompok beranggotakan 11 responden.Sampel diambil berdasarkan teknik purposive sampling yang mana sampel penelitian ini sudah memenuhi kriteria inklusi dan eksklusi yang telah ditetapkan oleh peneliti. Data yang didapatkan diolah dengan menggunakan uji normalitas data menggunakan Shapiro Wilk karena menggunakan sampel kurang dari 50. Selanjutnya dilakukan uji perbedaan pre test dan post test dengan menggunakan uji paired sample t-test karena data yang didapatkan berdistribusi normal. Kemudian dilakukan uji perbandingan efek antara MONAS dengan active exercise menggunakan uji independent sample t-test. Semua data diolah menggunakan SPSS 23.

\section{Hasil Dan Pembahasan}

Tabel 1. Pengaruh pemberian MONAS terhadap nyeri dan fleksibilitas

\begin{tabular}{lcc}
\multicolumn{1}{c}{ Kelompok } & Mean \pm SD & $p$ \\
\cline { 1 - 2 } Nyeri & & \\
\cline { 1 - 2 } Pre Test & $8,36 \pm 0,925$ & 0,000 \\
\cline { 1 - 2 } Post Test & $3,27 \pm 0,905$ & \\
\cline { 1 - 2 } Fleksibilitas & & \\
\cline { 1 - 2 } Pre Test & $2,827 \pm 1,0374$ & 0,000 \\
Post Test & $4,227 \pm 1,149$ & \\
\hline
\end{tabular}

Sumber: Data Primer 2019, Keterangan: SD = standar deviasi, $\mathrm{p}=$ paired $t$-test

Tabel 2. Pengaruh pemberian Active Exercise terhadap nyeri dan fleksibilitas

\begin{tabular}{lll}
\multicolumn{1}{c}{ Kelompok } & \multicolumn{1}{c}{ Mean \pm SD } & $p$ \\
\hline Nyeri & & \\
\hline Pre Test & $8,18 \pm 1,168$ & 0,000 \\
\hline Post Test & $3,27 \pm 1,009$ & \\
\hline Fleksibilitas & & \\
\hline Pre Test & $3,064 \pm 0,8789$ & 0,000 \\
\hline Post Test & $4,373 \pm 1,2076$ & \\
\hline
\end{tabular}

Sumber: Data Primer 2019,Keterangan: SD = standar deviasi, $\mathrm{p}=$ paired $t$-test 
Tabel 3.Perbandingan pemberian MONAS dan Active Exercise terhadap nyeri dan fleksibilitas

\begin{tabular}{lcc}
\hline \multicolumn{1}{c}{ Selisih Pre-PostTest } & Mean \pm SD & $\mathrm{p}$ \\
\hline Nyeri & $5,09 \pm 1,222$ & \\
\hline MONAS & $4,91 \pm 0,539$ & 0,658 \\
\hline Active Exercise & \\
\hline Fleksibilitas & $1,400 \pm 0,634$ & \\
\hline MONAS & $1,309 \pm 0,577$ & 0,729 \\
\hline Active Exercise & Sumber: Data Primer 2019, Keterangan: SD = standar deviasi, $\mathrm{p}=$ paired t-test
\end{tabular}

Hasil analisis menunjukkan bahwa hasil persentasi reponden laki-laki sebanyak 8 orang dan untuk responden perempuan sebanyak 14 orang. Hal ini sesuai dengan pendapat Andini (2015) yang menyatakan bahwa prevalensi LBP lebih banyak pada perempuan dibandingkan laki-laki. Hal ini karena kemampuan otot wanita lebih rendah dibandingkan pria dan pada wanita terjadi proses menopause yang dapat menyebabkan kepadatan tulang berkurang akibat penurunan hormon estrogen sehingga memungkinkan terjadinya nyeri pinggang (Fauzia, 2015).

Berdasarkan usia, yang memiliki jumlah responden terbanyak yaitu pada usia 56-65 tahun dengan 11 orang responden, selanjutnya pada usia 46-55 tahun dengan jumlah responden sebanyak 5 orang, usia 26-35 tahun dengan 4 orang responden dan kelompok usia paling sedikit yaitu usia 36-45 tahun dengan jumlah responden 2 orang. Penelitian dari Christy W. Nelman dalam Amrulloh (2017) menyatakan bahwa terdapat hubungan antara usia dengan keluhan nyeri punggung. Usia yang rentan terkena nyeri punggung yaitu usia 4065 tahun. Semakin bertambah usia responden maka keluhan akan semakin meningkat10.

Dengan meningkatnya usia seseorang maka, semakin tinggi resiko orang tersebut mengalami penurunan elastisitas karena terjadi degenerasi pada tulang yang berupa kerusakan jaringan, penggantian jaringan menjadi jaringan parut, dan pengurangan cairan yang merupakan pemicu timbulnya LBP (Fauzia, 2015). Berdasarkan jenis pekerjaan, ibu rumah tangga memiliki jumlah responden terbanyak yaitu 9 orang, kemudian karyawan dan wiraswasta dengan 4 orang responden, pensiunan sebanyak 3 orang responden, dan PNS dengan jumlah responden sebanyak 2 orang. Nyeri punggung dapat terjadi karena posisi duduk statis yang terlalu lama, sehingga menyebabkan beban postural yang berat. Kondisi ini akan mengurangi aliran darah ke otot sehingga mengakibatkan kelelahan otot (Natosba \& Jaji, 2016).

Berdasarkan hasil uji paired sampel t-test pada Tabel 1 menunjukkan bahwa sesudah diberikan MONAS didapatkan nilai signifikan $p=0,000$ yang menunjukkan bahwa ada perubahan bermakna sebelum dan sesudah MONAS. Hal ini sejalan dengan penelitian yang dilakukan oleh Poluan (2017) dimana dengan pemberian slump technique selama 6 kali perlakuan didapatkan penurunan skor nyeri sebesar 32,07\%, dimana sebelum perlakuan nilai rerata nyeri 67,35 dan sesudah perlakuan sebesar 45,755. Penelitian lainnya oleh Mishra, et al (2018) yang menyatakan bahwa slump technique efektif dalam penanganan LBP dimana slump technique dapat mengurangi nyeri yang dialami pasien akibat dari penekanan intranueral edema. Pada slump technique juga dapat mengurangi jaringan parut pada saraf dan struktur disekitarnya, serta mempengaruhi fleksibilitas otot punggung (Swati, 2018).

Berdasarkan hasil uji paired sampel t-test pada tabel 2 menunjukkan bahwa sesudah diberikan Active Exercise didapatkan nilai signifikan $\mathrm{p}=0,000$ yang menunjukkan bahwa ada perubahan bermakna sebelum dan sesudah Active Exercise. Hal ini sejalan dengan penelitian yang dilakukan oleh Choi, Gwon, Kim, Park, and Cho (2016)menyatakan bahwa latihan terapi aktif efektif untuk menurunkan nyeri, dimana sebelum perlakuan didapatkan skor nyeri dengan rerata 6,63 dan setelah perlakuan 
5,57. Selain itu juga terjadi peningkatan kekuatan otot dari 133,90 menjadi 145,59. Latihan ini dapat meningkatkan stabilitas inti tubuh serta memperkuat otot punggung secara signifikan sehingga dapat menurunkan nyeri dan juga dapat meningkatkan fleksibilitas 13. Pemberian AROMEX dapat meningkatkan dan mempertahankan kekuatan otot dan fleksibilitas sendi7.

Berdasarkan uji independent sampel t-test menunjukkan hasil pada nyeri diperoleh nilai $p=0,658$ sedangkan fleksibilitas $p=0,729$. Hal ini menunjukkan tidak ada perbedaan yang bermakna atau signifikan antara MONAS dan Active Exercise terhadap perubahan nyeri maupun fleksibilitas pada penderita LBP. Tidak adanya perbedaan yang signifikan antara MONAS dan active exercise dapat disebabkan oleh berbagai faktor. Beberapa faktor yang bisa menjadi pemicunya seperti sampel yang tidak homogen baik dari jenis LBP maupun usia responden yang beragam. Penderita LBP membawa permasalahan yang berbedabeda seperti LBP karena spasme otot, spondilosis bahkan HNP yang mengakibatkan prognosis tiap penderita berbeda- beda sehingga menjadi keterbatasan dalam penelitian ini. Usia mempengaruhi kemampuan tubuh untuk menerima respon dari perlakuan yang diberikan sehingga beberapa pasien ada yang cepat mengalami perubahan dan ada yang tidak. Selain itu, penelitian yang dilakukan di dua tempat berbeda juga dapat memengaruhi hasil dari penelitian, sebab yang memberikan perlakuan pada responden adalah orang yang berbeda. Pemberian terapi lain seperti modalitas fisioterapi (IRR dan Tens) juga dapat memengaruhi hasil penelitian yang diperoleh.

Berdasarkan uji deskriptif mean dan standar deviasi, menunjukkan MONAS lebih berpengaruh dibanding Active Exercise. Pada nilai nyeri, MONAS menunjukkan nilai yang lebih besar dibanding Active Exercise dengan selisih 0,18 0,683. Sedangkan pada fleksibilitas, MONAS juga menunjukkan nilai yang lebih besar dibandingkan Active Exercise dengan selisih 0,091 0,057. Sebesar 50\% sampel dalam penelitian ini adalah responden LBP yang disebabkan oleh HNP. Hal ini sesuai dengan latihan MONAS yang ditujukan untuk membebaskan iritasi saraf dari perlengketan, menormalkan konduktivitas dan mikrosirkulasi saraf, mobilisasi sendi dan otot, serta pemulihan fungsi saraf. Sedangkan Active Exercise lebih ditujukan untuk masalah LBP yang terkait dengan otot.

\section{Simpulan Dan Saran}

Peneliti menyimpulkan bahwa terdapat pengaruh MONAS dan Active Exercise yang signifikan terhadap nilai nyeri dan fleksibilitas antara sebelum dan sesudah perlakuan. Tidak ada perbedaan yang signifikan antara MONAS dan Active Exercise terhadap nyeri dan fleksibilitas. Latihan MONAS dan Active exercise bisa menjadi pilihan latihan pada penderita low back pain. Diperlukan penelitian lebih lanjut dengan sampel yang lebih banyak dan diagnosa yang homogen baik dari jenis LBP maupun usia responden. Disarankan untuk meneliti di satu tempat atau boleh beberapa tempat namun yang memberikan perlakuan adalah orang yang sama dan lebih mengontrol variabel-variabel perancu seperti aktivitas fisik, dan latihan selain yang dilakukan peneliti. Disarankan kepada masyarakat luas untuk menghindari posisi yang salah dalam melakukan aktivitas, dan menghindari postur tubuh yang buruk saat beraktivitas agar terhindar dari low back pain

\section{Daftar Rujukan}

Choi, H.-K., Gwon, H.-j., Kim, S.-R., Park, C.-S., \& Cho, B.-J. (2016). Effects of active rehabilitation therapy on muscular back strength and subjective pain degree in chronic lower back pain patients. Journal of physical therapy science, 28(10), 2700-2702.

Fauzia, A. (2015). Risk Factor of Low Back Pain In Workes. J Majority 4(1), 12-19. 
Kaur, K. (2016). Prevalensi Keluhan Low Back Pain (LBP) pada Petani di Wilayah Kerja UPT Kesmas Payangan Gianyar April 2015. Intisari Sains Medis, 5(1), 49-59.

Koes, I. (2017). Anatomi dan Fisiologi (Edisi Revisi). Bandung : Alfabeta.

Natosba, J., \& Jaji, J. (2016). Pengaruh Posisi Ergonomis terhadap Kejadian Low Back Pain Pada Penenun Songket di Kampung BNI 46. Jurnal Keperawatan Sriwijaya, 3(2), 8-16.

Poluan, W. Y., \& Aras, D. (2018). Pengaruh Mobilisasi Saraf terhadap Perubahan Nilai Nyeri pada Penderita Myogenic Low Back Pain. Media Kesehatan Politeknik Kesehatan Makassar,12(2), 69-74.

RI, K. K. (2013). Badan penelitian dan pengembangan kesehatan. Riset Kesehatan Dasar.

Safa'ah, N., \& Srimurayani, I. D. (2017). Effectiveness Of Isometric And Range Of Motion (Rom) Exercise Toward Elderly Muscle Strenght In Pasuruan Integrated Service Unit, Elderly Social Services In Lamongan. Biomedical Engineering, 3(1), 7-15.

Swati, M. (2018). Comparison between Mulligan Traction Leg Raise versus Slumps Stretching on Pain, Passive Leg Raise, and Functional Disability in Lumbar Radiculopathy. Journal of Medical Science and Clinical Research, 20.

Tanderi, E. A., Kusuma, T. A., \& Hendrianingtyas, M. (2017). Hubungan Kemampuan Fungsional Dan Derajat Nyeri Pada Pasien Low Back Pain Mekanik Di Instalasi Rehabilitasi Medik Rsup Dr. Kariadi Semarang. Jurnal Kedokteran Diponegoro, 6(1), 6372.

Yuliartha, I. N. O., Silakarma, D., \& Bagiada, N. A. (2017). Perbandingan Penambahan Pelatihan Mobilisasi Saraf Dengan Myofascial Release Pada Active Isolated Stretching Terhadap Peningkatan Fleksibilitas Otot Hamstring Pada Mahasiswa Program Studi Fisioterapi Fakultas Kedokteran Universitas Udayana. E-Jurnal Medika Udayana, 6(9). 
Lampiran;

Tabel Karakteristik Sampel Penelitian

\begin{tabular}{lcc}
\hline Karakteristik Sampel & Frekuensi & Persentase \\
\hline Jenis Kelamin & 8 & 36,4 \\
\hline Laki-laki & 14 & 63,6 \\
\hline Perempuan & 22 & 100 \\
\hline Total & & \\
\hline Usia & 4 & 18,2 \\
\hline $26-35$ & 2 & 9,1 \\
\hline $36-45$ & 5 & 22,7 \\
\hline $46-55$ & 11 & 50 \\
\hline $56-65$ & 22 & 100 \\
\hline Total & & \\
\hline Pekerjaan & 9 & 40,9 \\
\hline IRT & 4 & 18,2 \\
\hline Karyawan & 2 & 9,1 \\
\hline PNS & 4 & 18,2 \\
\hline Wiraswasta & 3 & 13,6 \\
\hline Pensiunan & 22 & 100 \\
\hline Total & & \\
\hline Sumber $:$ Data Primer 2019 & & \\
\hline
\end{tabular}

Sumber : Data Primer 2019

Tabel Distribusi perubahan nyeri sebelum dan sesudah pemberian MONAS

\begin{tabular}{lccccc}
\hline \multirow{2}{*}{ Kategori } & \multicolumn{2}{c}{ Pre Test } & \multicolumn{2}{c}{ Post Test } \\
\cline { 2 - 6 } & $\mathrm{n}$ & $\%$ & $\mathrm{~N}$ & $\%$ \\
\hline Tidak Nyeri & 0 & 0 & 2 & 18,2 \\
\hline Nyeri Sedikit & 0 & 0 & 8 & 72,7 \\
\hline Nyeri & 0 & 0 & 1 & 9,1 \\
\hline Nyeri Berat & 6 & 54,5 & 0 & 0 \\
\hline Nyeri Sangat Berat & 5 & 45,5 & 0 & 0 \\
\hline Total & 11 & 100 & 11 & 100 \\
\hline
\end{tabular}

Sumber: Data Primer 2019

Keterangan: $\mathrm{n}=$ jumlah sampel, $\%=$ persentase

Tabel Distribusi perubahan fleksibilitas sebelum dan sesudah pemberian MONAS

\begin{tabular}{lccccc}
\hline \multirow{2}{*}{ Kategori } & \multicolumn{2}{c}{ Pre Test } & \multicolumn{2}{c}{ Post Test } \\
\cline { 2 - 6 } & $\mathrm{N}$ & $\%$ & $\mathrm{n}$ & $\%$ \\
\hline Derajat I & 0 & 0 & 3 & 27,3 \\
\hline Derajat II & 4 & 36,4 & 5 & 45,5 \\
\hline Derajat III & 7 & 63,6 & 3 & 27,3 \\
\hline Derajat IV & 0 & 0 & 0 & 0 \\
\hline Total & 11 & 100 & 11 & 100 \\
\hline
\end{tabular}

Sumber: Data Primer 2019

Keterangan: $\mathrm{n}=$ jumlah sampel, $\%=$ persentase

Tabel Distribusi perubahan nyeri sebelum dan sesudah pemberian Active Exercise

\begin{tabular}{lcccc}
\hline \multirow{2}{*}{ Kategori } & \multicolumn{2}{c}{ Pre Test } & \multicolumn{2}{c}{ Post Test } \\
\cline { 2 - 5 } & $\mathrm{N}$ & $\%$ & $\mathrm{n}$ & $\%$ \\
\hline Tidak Nyeri & 0 & 0 & 3 & 27,3 \\
\hline
\end{tabular}




\begin{tabular}{lcccc}
\hline Nyeri Sedikit & 0 & 0 & 7 & 63,6 \\
\hline Nyeri & 1 & 9,1 & 1 & 9,1 \\
\hline Nyeri Berat & 5 & 45,5 & 0 & 0 \\
\hline Nyeri Sangat Berat & 5 & 45,5 & 0 & 0 \\
\hline Total & 11 & 100 & 11 & 100 \\
\hline
\end{tabular}

Sumber: Data Primer 2019 Keterangan: $\mathrm{n}=$ jumlah sampe, \% = persentase

Tabel Distribusi perubahan fleksibilitas sebelum dan sesudah pemberian Active Exercise

\begin{tabular}{lccccc}
\hline \multirow{2}{*}{ Kategori } & \multicolumn{2}{c}{ Pre Test } & \multicolumn{2}{c}{ Post Test } \\
\cline { 2 - 6 } & $\mathrm{N}$ & $\%$ & $\mathrm{~N}$ & $\%$ \\
\hline Derajat I & 1 & 9,1 & 4 & 36,4 \\
\hline Derajat II & 4 & 36,4 & 4 & 36,4 \\
\hline Derajat III & 6 & 54,5 & 3 & 27,3 \\
\hline Derajat IV & 0 & 0 & 0 & 0 \\
\hline Total & 11 & 100 & 11 & 100
\end{tabular}

Sumber: Data Primer 2019 